\title{
La esencia biosocial de la reproducción humana
}

\author{
Tito Méndez Jiménez*
}

\begin{abstract}
RESUMEN
El artículo comprende la discusión filosófica del problema de la esencia del proceso de la reproducción humana como fenómeno de profundo carácter biosocial, con prevalencia de las regularidades sociales, mismas que definen la "nueva" (superior) forma de reproducción de la materia viva -la social. Y no obstante en la Tierra habitan distintas especies de animales sociales, todas ellas se reproducen primordialmente dentro del ámbito de las leyes biológicas, es decir, en forma instintiva $\mathrm{y}$ en estrecha dependencia del medio ambiente. Únicamente el hombre (Homo sapiens) -hasta donde sabemos- evolutivamente optó por autorreproducirse mediante la concreción de la unidad de dos formas de movimiento que mutuamente se niegan y, a la vez, se complementan entre sí: la biológica y la social.
\end{abstract}

Palabras claves: esencia biosocial, reproducción humana, evolución, sustancia, energía.

\section{ABSTRACT}

The biosocial essence of human reproduction. The article includes the philosophical discussion of the problem of the essence of human reproduction as a phenomenon of deep biosocial character, with the prevalence of social regularities, the same which define the "new"(superior) reproduction form of the live matter -the social. And yet on the earth inhabit different species of social animals, all of them reproduce primarily within the domain of biological laws, meaning in an instinctive way and in close dependence on the environment. Only man (Homo sapiens) -as far as we know- evolutionarily chose to reproduce itself through the concretion of the unity of two forms of movement which mutually deny themselves and at the same time complement each other: The biological and the social.

Key words: Essence, biosocial, human reproduction, evolution, substance, energy.

* Doctor en Filosofía por la Universidad Estatal de Kiev, República de Ucrania y Master of Science en Biología; Zoólogo, por la Universidad Estatal de Odesa, República de Ucrania. Profesor de Filosofía y Biología en el Instituto Tecnológico de Costa Rica (ITCR) entre 1991-1995. Actualmente es profesor de Filosofía y Biología e investigador de la Universidad Estatal a Distancia (UNED) de Costa Rica. 


\section{"Reproducción" como categoría filosófica}

El término "reproducción" se presenta como elemento enriquecedor y expresión concreta y actual del principio general del desarrollo, empleado en filosofía para la explicación inductiva del proceso de transmisión de la forma y del contenido, de la estructura y la función (información sobre la totalidad) de una cosa (sistema) hacia otra de su misma naturaleza, de un ser singular o su conjunto a otro $\mathrm{u}$ otros, tanto en un ámbito concreto como en su manifestación general. La reproducción se presenta como concepto filosófico fundamental o, dicho en otras palabras, adquiere estatus de categoría, cuando discernimos la ruta del desarrollo de la materia en el nivel biológico de su movimiento, obteniendo total contenido en el momento de su extrapolación a la arena social, donde se convierte en término cuyo significado es dual, es decir, biológico y social. El contenido biosocial del concepto reproducción, mediante inferencia, se puede obtener de la sentencia que Federico Engels anotara en el prólogo a la primera edición de su trabajo $<$ El origen de la familia, la propiedad privada y el Estado:

"Según la teoría materialista, el factor decisivo en la historia es, en fin de cuentas, la producción y la reproducción de la vida inmediata.
Pero esta producción y la reproducción son de dos clases. De una parte, la producción de medios de existencia, de productos alimenticios, de ropa, de vivienda y de los instrumentos que para producir todo eso se necesitan; de otra parte, la producción del hombre mismo, la continuación de la especie" (Marx, Engels, 1983: 471-2).

En realidad, el segundo momento del fenómeno observado por Engels es inseparable de su primera manifestación. No obstante, el objeto de nuestro estudio corresponde precisamente a la "producción de la humanidad misma”, cuyo análisis exige la abstracción sistematizada de la "producción de los medios de existencia”; mas no sería racionalmente correcto olvidar por completo este problema, ya que su observancia metodológica se hace necesaria cuando se estudian los caracteres socioeconómicos que se presentan durante el desarrollo de la humanidad, los cuales son determinantes en la definición actual del proceso de su reproducción.

Así pues, en la filosofía dialéctico-materialista el concepto biológico "procreación", que significa la transferencia de masa y energía (información genética) de un organismo a su descendiente en el ámbito poblacional de cualquier especie de planta, animal, hongo o bacteria, adquiere un significado más general, es decir, más abstracto - "reproducción”. Por eso decimos que para la 
filosofía materialista el conocimiento de las leyes de la reproducción de la materia misma, como fenómeno integral, reviste gran importancia. En el orden biológico la procreación se presenta a nivel de los organismos, inclusive cuando en ella se observa contacto grupal entre individuos, e incorrecto sería afirmar que las colonias procrean, y más aún si se tratara, digamos, de poblaciones, especies, biocenosis o biósfera en su totalidad. A los niveles superiores de organización de los sistemas vivos les son característicos procesos dirigidos de sostén y aumento de su masa mediante la recuperación constante de sus elementos estructurales y funcionales, conservando así su unidad orgánica. Aquí se realiza el mecanismo de transferencia no sólo de la información interna (genética), sino que, además, se transmite información sobre el estado del medio ambiente como resultado de su reflejo en los seres vivos, lo que con el tiempo puede fijarse genéticamente:

"Los animales durante el proceso de evolución adaptativa sobre la base de la herencia y de la experiencia propia, o sea durante el proceso de aprendizaje, estructuraban el modelo interno del mundo exterior" (Dubinin, 1981: 103).

Similar esquema del fenómeno analizado puede emplearse en relación con la transmisión de información en los sistemas sociales.
Por consiguiente, de esta forma fluye el proceso de reproducción de los sistemas vivos y sociales, el cual, como ya fue anotado, contiene en sí el proceso de procreación de los individuos (elementos), más el fluido de información que se transmite constantemente sobre el mundo circundante en forma de impulso afectivo (Scheler, 1972: 33) o reflejo irritativo (característico en las plantas y animales inferiores), incondicional-instintivo (en los animales) y condicional-psíquico (en animales superiores, nivel organizativo que incluye al hombre), fenómeno que se manifiesta como resultado de su actividad adaptativa. Valga anotar el papel integrador que algunos autores reconocen en el instinto como mecanismo de regulación de la vida en sus diversos estadios de desarrollo, incluido el psíquico, en donde

“...toda sensación, toda percepción, como igualmentetodo proceso de una unidad funcional fisiológica, vienen condicionados por el instinto, y los instintos son, precisamente, los que constituyen la unidad del organismo psicofisico" (Scheler, 1967: 44).

En el tapete de la discusión quedaría el problema de la relación contradictoria, muchas veces antagónica, que surge a partir de la lucha dialéctico-existencial (ontológica) entre los instintos y la razón, ejercicio reflexivo que haré en otro momento. 
Todas las formas superiores de organización de la materia viva contienen en sí las formas inferiores de su reflejo; algo así como el principio de correspondencia de Niels Bohr aplicado a la interpretación dialéctico-metodológica de las teorías científicas, en donde el desarrollo del conocimiento se sustenta sobre la base correlativa entre la novedad gnoseológica y su acervo histórico, poniéndose en evidencia -mediante el reflejo sistematizado de la razón- la naturaleza objetiva del mundo a partir de los niveles de su organización; es decir, las nuevas teorías sobre determinado objeto de estudio no sólo difieren, superan o niegan dialécticamente a sus precedentes, sino que, además, las contienen y conservan en el ámbito correspondiente, permitiendo su análisis inverso como prueba de veracidad científica y unicidad del mundo. Así pues, con respecto a la vida sociorracional, podemos afirmar con el filósofo Scheler, que:

"el hombre contiene todos los grados esenciales de la existencia, $y$ en particular de la vida; y en él llega la naturaleza entera (al menos en las regiones esenciales) a la más concentrada unidad de su ser" (Scheler, 1972: 33).

Empleando términos aún más generales, en sus reflexiones bioéticas, Blázquez reafirma dicha verdad:
"A nivel ontológico, el principio orgánico de la vida (humana- t.m.) ${ }^{1}$ se ha de entender como un todo autodinámico o capacidad activa orientada hacia la plenitud racional." (Blázquez, 2000: 125).

A lo planteado es necesario agregar que el concepto reproducción, cual instrumento gnoseológico que explica el fluir de la materia en sus formas de existencia viva y social, del mismo modo metodológico, permite el estudio concreto de una de las manifestaciones de la esencia de la vida -la reproducción adaptativa, que en determinada medida explica la esencia del ser humano en tanto producto de la evolución psicosomática, pues:

"los antepasados guardan una función intrínseca "transformante y determinante" hacia los generados... La evolución es ante todo, génesis evolutiva de formas que provienen de otras, que desde si mismas hacen brotar la nueva transformación: situación que va más allá de la esencia constitutiva especiable o quiddificable, la cual engendra individuos de la misma estructura. La evolución es nacimiento de una nueva forma especifica: en la psique y en el soma." (Giralt, 1975: 65).

Por ello, con propiedad, es factible definir la reproducción como una forma ilustrativa de manifestación

1. Aclaración del autor. 
de la esencia de la vida individual y social, aunque en el hombre su acontecer sea, como lo anota el existencialista José León Mora Barberena, ontogenética y filogenéticamente de carácter negativo, producto de su debilidad embrionaria durante el proceso de formación como sujeto social (Mora, 1964: 10-11). De lo expresado resulta claro el porqué dicho concepto, cuando comprende la vida humana y se analiza más allá de los relativismos biologizadores, o moralistas (Blázquez, 1984: 438), deviene en profundo carácter biosocial y así su esencia.

\section{De la reproducción de la materia viva a la reproducción del hombre}

En el artículo introductorio " $\mathrm{La}$ reproducción humana en la revolución científico-técnica" fue considerado el significado determinante que representa el trabajo en el proceso histórico de formación del hombre como negación del estadio biológico del desarrollo de la materia y la construcción de su ser a partir del sustrato biológico negado. También fue subrayado y el papel que jugó el trabajo en la realización de las funciones de la reproducción humana (Méndez, 2002).

Es necesario profundizar en el análisis de aquellos factores evolutivos de la biósfera (macroevolución) que algún día fundaron las condiciones para el salto cualitativo hacia la megaevolución o evolución de la noósfera, es decir, a la evolución biosocial humana (Iugai, 1985: 205). Este procedimiento permite acercarse con propiedad al problema de la implantación cualitativa de una nueva forma de reproducción de la vida sobre la base de la acumulación concatenada de premisas biopsíquicas.

La pregunta sobre el origen del hombre, sobre su aparición como factor geológico (Vernadski, 1977: 19) y su evolución fue planteada ya por los materialistas franceses del siglo XVIII: (Holbach, 1963: 123, 128-30), (La Mettrie, 1976: 148-51, 258-61, 451) y otros, y científicamente argumentada por los fundadores de la teoría de la evolución (Lamarck y Darwin) a finales del siglo XVIII y principios del XIX. Valga recalcar, además, que la más auténtica fundamentación científica a esta pregunta aparece en la teoría de la evolución de Carlos Darwin, la cual fue publicada en 1859. En ella, concretamente, el problema se refleja en la obra El origen del hombre. La selección natural y la sexual. En dicho trabajo Darwin escribió:

"La poca fuerza corporal del hombre, su escasa velocidad en la locomoción, su carencia de armas naturales, etc., están compensadas con exceso: primero: por sus fuerzas intelectuales, que le han permitido, aun en su estado salvaje, fabricar armas, útiles, etc., y, segundo: por 
sus aptitudes sociales que le han impulsado a ayudar a sus semejantes, y a recibir, en pago, ayuda de ellos" (Darwin, 1977: 130).

Finalmente, el primer filósofo que desde posiciones marxistas planteó la pregunta sobre la aparición de la forma social pensante de movimiento de la materia fue Federico Engels en su artículo "El papel del trabajo en el proceso de transformación del mono en hombre", donde brillantemente generalizó el material científico que sobre la evolución del hombre había sido acumulado hasta los años 70 del siglo XIX, demostrando de esta manera su esencia biosocial:

"Mediante la combinación de la mano, los órganos lingüísticos y el cerebro, y no sólo en el individuo aislado, sino en la sociedad, se hallaron los hombres capacitados para realizar operaciones cada vez más complicadas, para plantearse y alcanzar metas cada vez más altas" (Engels, 1982: 149).

Cualitativamente hablando, es importante anotar que las características sociales, mediante las cuales los homínidos resultaron el género más fuerte entre los animales, permitieron el inicio del proceso de reproducción a gran escala de una nueva forma de energía biogeoquímica, denominada por Vernadski "energía de la cultura humana, o energía cultural biogeoquímica" (Vernadski, 1977: 95).
Formas embrionarias de vida social existieron hace muchos cientos de miles de años, lejos de aquel tiempo al que hiciera referencia Engels; por ejemplo, los insectos sociales, algunas especies de aves y mamíferos superiores. Así:

"en una fase que aún no puede determinarse con certeza de aquel periodo de la Tierra a que los geólogos dan el nombre de periodo terciario (hoy - finales del neógeno- t.m.) ...vivió en alguna parte de la zona cálida de nuestro planeta... un género de monos antropoides muy altamente desarrollados" (Engels, 1982: 142).

Aquí el filósofo describe aquel "momento" del tiempo geológico que, producto de la acumulación de eventos necesarios y casuales en la naturaleza viva, generó condiciones óptimas para que de pronto -según dichas dimensiones temporales- pudiera suceder en determinado lugar un salto cualitativo en las interrelaciones entre una o varias manifestaciones de vida social prehumana y la naturaleza. Por cierto, no se descarta la posibilidad de que dichas condiciones pudieron existir al mismo tiempo en varios puntos geográficos de los continentes de entonces (acerca de ello hay testimonios científicos) o en tiempos distintos, lo que pudo haber producido la aparición de la prenoósfera más de una vez y en diversos lugares. Es indiscutible el hecho de 
que las premisas biológicas (elementos sociales en el seno de los sistemas biológicos) de la posible formación de sistemas sociales autorregulados en algún momento existieron en nuestro planeta y que, como resultado de su desarrollo posterior, apareció la vida prerracional, la cual con el tiempo resultó victoriosa en la "lucha por la supervivencia". Al principio ésta se reproducía bajo fuerte presión de la selección natural.

No procede dudar del hecho de que de las posibles apariciones de la noósfera, únicamente una se ha desarrollado hasta nuestros días, perpetuando su género y acumulando cada vez más información (negentropía) dentro de sí, sobre sí y sobre la naturaleza en enlace mutuo con la entropía social generada en el sistema. Estos argumentos gozan de veracidad científica. En este sentido, el científico ruso P. I. Boriskovski escribió:

"A finales del neógeno y en el límite entre el neógeno y el eopleistógeno en África, al sur de Europa y al sur de Asia vivieron distintas especies de homínidos cuya estructura fisica $y$ formas de vida mostraban principios de humanización... La inmensa mayoría de ellas desapareció sin dejar descendientes, resultó absorbida por el proceso de selección, no pudo sobrevivir y adaptarse a las condiciones cambiantes de la vida" (Boriskovski, 1979: 25).

Al principio la actividad adaptativa de los monos arborícolas -posibles antecesores del hombrepertenecientes a la familia Hominidae y la selección natural, cada vez más, fijaban y desarrollaban en ellos el comportamiento psicológico, diferenciando profundamente las funciones de las manos y los pies (Engels, 1982: 143):

"El phylum humano que procede de otros phyla animales...va a mostrar en su desarrollo arborescente una serie de tipos cualitativamente distintos en su psiquismo y en su morfología somática” (Giralt, 1975: 64).

Como resultado de ello, las manos, a diferencia de los pies, comenzaron a realizar nuevas y más complejas operaciones dirigidas a la obtención de alimento, a la defensa, a la comunicación y a la protección de su descendencia. A consecuencia de esto, las manos se desarrollaron cuantitativamente (aumentó su tamaño, se reestructuraron los músculos y los huesos) y cualitativamente (cambiaron su forma y funciones). Después:

"estos monos... fueron perdiendo, al encontrarse sobre el suelo, la costumbre de servirse de las extremidades superiores para andar y marcharon en posición cada vez más erecta. Se habia dado, con ello, el paso decisivo para la transformación del mono en hombre" (Engels, 1982: 142). 
Lo argumentado nos permite concluir acerca de los principios ontológicos del proceso adaptativo de humanización antropoide, fenómeno que no se dio sin un acelerado gasto energético de carácter biopsicológico por parte de nuestros ancestros, que sufrían la trama de la asimilación de un nuevo hábitat y la articulación, por ende, del nicho ecológico correspondiente en un medio adverso por desconocido y agreste, lo cual, a la vez, les generó cambios somáticos y de conducta:

"El origen del hombre no está en el hecho de haber logrado la posición erguida de su cuerpo: por el contrario, al ir tomando el cuerpo un aspecto humano, el hombre se irguió..." (Bolk, 1971: 12-13).

Por razones aún desconocidas para la ciencia, los antepasados del hombre empezaron gradualmente a descender de los árboles a la tierra; como que regresaban a su viejo nicho ecológico en el suelo. Por supuesto, el prolongado período transicional incluía a la vez la existencia de antropoides tanto sobre los árboles como en la tierra. (Por lo visto, los monos antropomorfos actuales se encuentran en este estadio de su evolutiva “humanización"). La vida arborícola de estos animales fue siendo desplazada por la terrestre, es decir, de los árboles se trasladaba a su medio natural contrario y primigenio -la vida en el suelo. Por ahora únicamente podemos especular acerca de los motivos que obligaron el retorno a tierra de los predecesores del hombre. El estudio de la vida de nuestros hermanos de orden (Primates) ayuda en la búsqueda de tales razones. Probablemente ellos, habiendo descendido de los árboles, durante mucho tiempo aún se reproducían sobre éstos, mientras no contaran con las condiciones necesarias para la reproducción total en su nueva casa. Cabe suponer que el regreso de los homínidos a la tierra no fue precisamente porque aquí encontraran condiciones óptimas de vida, sino porque fueron desplazados por antropoides más competitivos $\mathrm{y}$, por ende, más desarrollados psicológicamente; o bien, como resultado del desplazamiento de los individuos más débiles dentro de la misma especie, producto del aumento poblacional, proceso que pudo generar la formación de colonias independientes $\mathrm{y}$, más tarde, poblaciones de monos trasladándose por el suelo. No olvidemos que hoy por hoy la base alimenticia de los monos, su fuente energética, sigue estando en las copas de los árboles.

En la medida en que las investigaciones biológicas avanzan, concretamente en los campos de la anatomía comparada, paleozoología, paleoantropología, fisiología y morfología comparadas y la biología molecular, mi suposición se aproxima al salto cualitativo que históricamente ha caracterizado el paso del 
conocimiento filosófico, fundado en el reflejo racional de la realidad objetiva (Lenin, 1989: 133-142), hacia su ordenamiento científico. Las investigaciones del naturalista y pensador Louis Bolk acerca de los orígenes del hombre refuerzan los criterios vertidos. Su hipótesis sobre la "fetalización humana" y el concepto de "retraso evolutivo o principio de inhibición”, que consisten en la conservación de los caracteres fetales primarios y la determinación por éstos de los caracteres consecutivos, por ejemplo la erguidez del homínido, producto de la acción de un factor inhibidor, plantean el problema del rezago filogenético del ser humano: “... desde el punto de vista corporal, el hombre es un feto de primate que ha alcanzado la madurez sexual. De ello se deducirá, necesariamente, que nuestros antepasados poseían ya todos los caracteres específicos primarios de la raza humana de hoy, pero sólo durante un corto período de su desarrollo individual...Cuando un carácter fetal se torna permanente, es porque una causa activa frena su desarrollo inicial y lo detiene, más o menos lejos de su culminación. La forma humana, en su totalidad, es consecuencia de una inhibición general del desarrollo..." (Bolk, 1971: 12-16).

El análisis da por sentado que, por presión del mecanismo de selección natural, de nuestros antepasados a la tierra regresaron los individuos más débiles. No obstante lo anterior, ellos también poseían un alto grado de desarrollo en su comportamiento psicológico y elementos de actividad social (vivían en manadas, respetaban cierta jerarquización organizacional, se defendían colectivamente de los enemigos y del mal tiempo, en conjunto buscaban alimento y velaban por sus hijos).

"En los animales superiores y, principalmente, en el hombre, -escribe E. Mayr-, se manifiesta la tendencia a suplir el tipo rígido de comportamiento genéticamente predeterminado por el que responde al aprendizaje y a la costumbre. En el proceso de esta forma de evolución el programa genético "cerrado" gradualmente es cambiado por un programa "abierto", estructurado de tal forma, que es capaz de registrar nueva información" (Mayr, 1968: 504).

Los antropoides que permanecieron básicamente en los árboles sobrevivieron hasta hoy y continúan desarrollándose por diferentes líneas genealógicas.

El sustrato biosocial humano fue preparado; en el interior de la biósfera se desarrollaba racionalmente el fenómeno de su contrario. En la lucha de los contrarios se resolvía la contradicción a favor de las regularidades sociales, y se inició el proceso de metasocialización de la materia viva. Una pequeña parte de la biósfera 
gradualmente se convertía en noósfera, se inició el desarrollo (evolución) consciente de la segunda forma de la materia autoorganizada -la forma social de su movimiento.

El paso de los primeros homínidos a la vida terrestre no se dio sin obstáculos. Éstos tuvieron que readaptarse a las nuevas condiciones de existencia, entre ellas, la más importante: luchar con otros animales por un lugar en la nueva casa. El origen de la noósfera está relacionado, precisamente, "con esta lucha del hombre con los mamiferos por el territorio" (Vernadski, 1977: 46). Habiendo vencido a los mamíferos y conquistado para sí el hábitat terrestre, los antepasados del hombre fueron reproduciéndose cada vez más en ese lugar. Esto sucedió en aquel período evolutivo durante el cual el hombre, con su trabajo y organización, pudo defender su descendencia de los enemigos y de las inclemencias del medio. El proceso de la totalidad reproductiva humana en las nuevas condiciones requirió del desarrollo posterior del lenguaje, de algunos órganos y sistemas de órganos (manos, cerebro) y del organismo como un todo. Por ejemplo

"el cerebro se presenta como producto y como una especie de "reservorio" de experiencia evolutiva derivada de la capacidad adaptativa de los animales, como órgano especializado de movimiento y regulador de su comportamiento" (Efimov, 1981: 89).

Al mismo tiempo,- y aquí aparece reflejada la relación inversa,- un organismo más negentrópico aceleraba el desarrollo de las relaciones sociales de los homínidos, permitiendo la formación de la razón, la cual realizaba concientemente su propósito (Giosler, 1967: 246) y procuraba efectividad en su reproducción.

Ahora podemos enumerar tres estadios en la evolución del proceso de la reproducción humana:

1. reproducción biológica con elementos discretos de organización social (vida en los árboles, aquí aún no se da la ramificación de los antropoides) $)^{2}$;

2. reproducción de los homínidos parcialmente en los árboles y en la tierra con expresiones notorias de vida social (estadio de transición);

3. reproducción de los homínidos únicamente en el suelo con predominio de la forma social de organización (el desarrollo del cerebro conlleva a la aparición de la razón).

2. P. I. Boriskovski considera que en este estadio, 10-14 millones de años atrás, en los bosques tropicales vivió el antepasado del hombre "Ramapithecus", cuya línea ya se había separado de los ancestros de los monos actuales, conservando aún su estado de mono antropoide /23, p. 19-20/. 
De esta manera surgió en la Tierra el nivel superior de organización (que conocemos) de la materia -la noósfera.

\section{La esencia de la reproducción humana}

Habiendo analizado el significado del concepto reproducción, el cual explica las regularidades del proceso de transferencia de masa y energía (información) dentro de los sistemas biológicos y biosociales, prolongando así su existencia y permitiendo el sostén de su funcionalidad (organización), y tomando en cuenta el salto cualitativo sufrido por la materia viva como consecuencia del cúmulo de causas determinadas (necesarias) y casuales, lo que desde el interior de la misma biósfera produjo la manifestación de un nuevo tipo de organización de la vida -la vida social, procedemos a la discusión del problema de la reproducción del hombre basándonos en su esencia biosocial.

La esencia del proceso de reproducción humana se define a partir de la esencia misma del hombre, la cual, como ya se dijo, por su carácter adaptativo, coincide con la esencia de la vida. Así como el fundamento profundo del hombre por sí mismo resulta biosocial por su forma y adaptativo por su función, entonces podemos partir de estas mismas premisas como los momentos más relevantes y necesarios en la revelación de la esencia de la reproducción socioantrópica. En la literatura filosófica y científica natural el problema del hombre como esencia biosocial aparece suficientemente ilustrado en los siguientes trabajos: (Engels, 1982), (Vernadski, 1977), (Iugai, 1985), (Alexeiev, 1969), (Stine Gerald James, 1977), (Darwin, 1953), (Mayr, 1968), (Boriskovski, 1979), (Efimov, 1981), (Dubinin, 1983), (Wilson, 1978), (Dubinin, Shevchenko, 1976), (Kalaikov, 1984), (Kostov, 1982), (Kuczynski, 1974), (Bertalanffy, 1981), (Löther, 1974), (Andreev, 1988), (Lomov, 1977), (Severtsev, 1922), (Efimov, 1981), (Mayr, 1981), (Scheler, 1967 y 1972), (Bolk, 1971) y otros. Exigua resulta la producción académica relacionada concretamente con la problemática de la esencia de la reproducción humana: (Kulikova, 1969), (Muraviov, 1978), (Pletnikov, 1983), (Rubin, 1971), (Méndez, 1989).

La reproducción del hombre consiste en el fluir de su sustancia, su energía y, con ellas, de la más compleja información, producto del autodesarrollo de la única especie viva perteneciente al género "Homo" y a la familia "Hominidae". Dicho proceso se da a través de la lucha en unidad de dos estados contrarios del sistema, característicos a las formas viva y social de movimiento -entropía y negentropía. Este fenómeno se manifiesta mediante el funcionamiento de todo el organismo 
y a partir del aparato genético que trasmite su propio sustrato (genotipo) de los progenitores al nuevo organismo. Esta incompleta definición de la reproducción humana se refiere únicamente a su aspecto biológico. Desde este punto de vista, el Homo sapiens representa

"un sistema cerrado compuesto por poblaciones autorreproductivas, entre las cuales se da el intercambio de genes. Habiendo sido por ello aislado de las demás especies animales, él no se cruza con ellas. El hombre racional se desagrega en razas, formadas a raíz del relativo aislamiento de distintas poblaciones, en las cuales se acumulaban algunos paquetes de genes. Sin embargo... la especie Homo sapiens no es una unidad de evolución biológica" (Dubinin, 1983: 38-9).

Recordemos que "el hombre es un ente biosocial, que en su formación y desarrollo como ser social los factores sociales son determinantes" (Iugai, 1985: 204).

El proceso de reproducción del hombre también incluye en sí y el factor humano, o sea el factor determinante en última instancia, el que actúa racionalmente con su nivel característico de conciencia. Para desentrañar el segundo aspecto del proceso de reproducción de la sociedad nosotros apelamos, nuevamente, al estudio de la esencia humana, pero ahora abstrayéndonos de sus premisas biológicas.
De esta forma, eludiendo cualquier teoría idealista, filósofo-antropologista, biologizadora (reduccionista) u otras teorías metafísicas sobre el hombre, el marxismo-leninismo, fiel a la sentencia del primer filósofo de la antigua Atenas -Sócrates: "conócete a ti mismo" (Chanyshev, 1981: 225), desde sus orígenes ha dedicado los mejores esfuerzos teóricos al problema del hombre. Es menester agregar que, a diferencia del enfoque moral socrático y de otros tratamientos unilaterales o limitados, el marxismo estudia al ser humano en forma integral, desde todo ángulo, en movimiento y desarrollo, en concatenación con el mundo material, dirigiendo así su potencial gnoseológico directamente hacia el hombre, o indirectamente, estudiando su mundo circundante. V. I. Lenin escribía:

"Para conocer realmente el objeto de estudio es necesario abarcar, estudiar todos sus aspectos, todos los enlaces y "mediaciones" ...la lógica dialéctica exige tomar el objeto en su desarrollo, "automovimiento" y sus transformaciones" (Lenin, Obras completas: 290).

En su tiempo Marx argumentaba que:

"la esencia humana no es algo abstracto inherente a cada individuo. Es, en su realidad, el conjunto de las relaciones sociales" (Marx, 
Engels, 1983: 25). Además, "a las personas se les puede diferenciar de los animales por su conciencia, su religión... Ellas mismas empiezan a diferenciarse del animal en el momento en que comienzan a producir los medios necesarios para la vida..." (Marx, Engels, Obras completas: 19).

El factor social como momento determinante en la confirmación de la esencia humana es subrayado por muchos pensadores y científicos actuales, como por ejemplo: (Vernadski, 1977: 44), (Severtsev, 1922: 52), (Dubinin,1983: 51, 64; 1976: 7, 1516, 156, 188; 1981: 103, 109; 1971), (Sklovski, 1987: 158), (Iugai, 1985: 204, 235), (Mayr, 1968: 504; 1981: 30), (Boriskovski, 1979: 29), (Louis, 1964: 33, 47), (Kalaikov, 1984: 46, 82, 93; 1983: 16), (Efimov, 1981: 114). Elocuente en este sentido resulta el criterio sobre la relación ontológica cuerpo-alma, cuando se afirma que

“...el principio del pensamiento, el alma racional, es la forma esencial del cuerpo humano...lo específico en una cosa es su forma esencial; luego, el principio del pensamiento, el alma racional, es la forma esencial del hombre, el aspecto más importante y sublime de él" (Araya, 1991: 92).

Más terrenal luce el discurso de la filósofa Giralt, que valiéndose del análisis dialéctico de la misma relación, sentencia:

"Hay una exigencia mutua entre la psique y el soma...La razón no es más que una inteligencia de grado avanzado de reflexión y de pensamiento abstracto, alcanzado sólo después de un largo proceso de evolución genética dentro del phylum humano" (Giralt, 1975: 64-66).

Opuesta al pensamiento optimista citado anteriormente es la idea que define al hombre como:

"un desertor de la vida, que habiendo exaltado morbosamente el sentimiento de su propio ser, se vale, para vivir, de meros sucedáneos (idiomas, herramientas), sustitutivos de las auténticas funciones y actividades vitales, capaces de desarrollo; es un viviente que ha desertado de la vida, de sus valores fundamentales, de sus leyes, de su sentido "sagrado", cósmico" (Scheler, 1967: 55-56).

El lado social de la reproducción del hombre desde el punto de vista filosófico fue trabajado por N.P. Dubinin en su teoría sobre la herencia social y sobre el programa social a principios de los años setentas del siglo XX (Dubinin, 1971, 1972). En la obra Algunas cuestiones de la naturaleza biosocial del hombre, Dubinin e Iu.G. Shevchenko escriben:

"Para el entendimiento de la correlación entre lo social y lo biológico en el hombre es importantísimo un 
principio, hasta hoy mal entendido, según el cual los resultados de la actividad sociolaboral, como lo muestran las leyes genéticas, no pudieron registrarse en los genes, es decir, no resultaron sujetos de la evolución biológica; pues esto se realiza mediante la transmisión de generación en generación de la experiencia social, situación que desembocó en la articulación gradual de un complejo programa social el cual es trasmitido a través de la educación" (Dubinin, Shevchenko, 1976:16).

Del postulado arriba mencionado se puede concluir que la reproducción social del hombre es el fluir de la información en forma de herencia social codificada en el programa social, la cual es transferida de generación en generación mediante la lucha dialéctica de la negentropía y entropía sociales (progreso y regreso) en el proceso de enseñanza y educación. La historia de la humanidad demuestra que, hasta ahora, a pesar de la presencia de manifestaciones regresivas en el desarrollo de la sociedad (guerras, colonialismo, esclavitud, racismo, fascismo, inquisición, etc.), el progreso se ha abierto camino venciendo en la lucha contra el mal. Y si la idea es la conservación de la especie humana, anhelo que se expresa primordialmente en el sostén del proceso de reproducción social, ante nosotros hoy se presenta el problema más importante e impostergable: es necesario triunfar en la lucha contra un nuevo mal -la crisis ecológica, que es producto del desarrollo irracional del fenómeno sociorreproductivo, el cual se presenta en forma de revolución científico-tecnológica.

De tal manera, la reproducción humana no es un fenómeno constituido por dos procesos separados, independientes uno del otro, autofuncionales, de herencia biológica y social. Desde el punto de vista metodológico, el estudio del proceso de reproducción de la sociedad fuera de la profunda unidad dialéctica que caracteriza a sus dos formas de expresión -la biológica y la socialrepresenta una clara manifestación del pensamiento metafísico con las consecuencias que de ello se derivan: sociologismo, vitalismo, cientismo, reduccionismo y demás concepciones anticientíficas.

Por ejemplo, iniciando con Spencer, los neodarwinistas explican la vida social a partir de posiciones biologizadoras puras, en forma mecánica se esfuerzan por traducir (reducir) las regulaciones sociales a las biológicas. Contrario a los neodarwinistas, Freud y los neofreudianos destacan la psiquis humana como una fuerza autosuficiente, independiente de sus bases biológicas, lo que les permite acercarse al problema del hombre en forma psicoanalítica. Finalmente, algunos existencialistas se presentan como apologetas del espíritu humano, el cual existe por sí mismo y sin casi nada que lo condicione: 
"Lo que hace del hombre un hombre es un principio que se opone a toda vida en general; un principio que, como tal, no puede reducirse a la "evolución natural de la vida"...Ya los griegos sostuvieron la existencia de tal principio y lo llamaron la "razón”...” (Scheler, 1972: 54-55).

Los factores biológico y social de la reproducción humana, a pesar de ser contradictorios, de negarse mutuamente (contrarios), no pueden manifestarse fuera de su unidad orgánica. Ellos se compenetran uno al otro, se intermedian y condicionan mutuamente. No podemos hablar de reproducción del hombre sin la presencia de su programa social; tampoco habrá reproducción de la sociedad sin la trasmisión de la información genética. Durante el desarrollo histórico del proceso de reproducción del hombre dichos factores se contradecían entre sí y con el medio natural (Kalaikov, 1984: 73).

La naturaleza biosocial del hombre, cuya esencia es adaptativa, es investigada por distintas áreas del saber filosófico, entre ellas la filosofía del hombre (Antropología filosófica), la filosofía del ser (Ontología o Primera filosofía), la teoría del conocimiento (Epistemología), la filosofía del proceder humano (Ética), la de la ciencia, entre otras. De esta premisa, deductivamente se concluye que la reproducción humana es un fenómeno biosocial adaptativo que expresa el momento funcional más importante de la esencia misma del hombre. Según opinión de P. Kostov, la naturaleza humana, y por ende la naturaleza de su reproducción, puede ser definida como:

"una unidad especifica doble de la morfofisiología humana y las acciones e interrelaciones sociales realizadas por el hombre dentro de la colectividad" (Kostov, 1982: 87). "El hombre es un eslabón natural en la evolución de la vida en la Tierra regido por las leyes biológicas del nacimiento, la vida y la muerte" (Dubinin, Shevchenko, 1976: 5).

El filósofo búlgaro I. Kalaikov argumenta lo siguiente:

"Como componente de la adaptabilidad social, la reproducción de la gente depende totalmente de la relación colectiva gracias a la cual se suple la reproducción de la vida humana, tanto a nivel individual como social” (Kalaikov, 1984: 82).

La reproducción del hombre es un proceso adaptativo de transferencia de información biológica y social de una generación a otra en el ámbito de las poblaciones humanas. El factor principal en este proceso es la totalidad de las relaciones sociales correspondientes a determinado modo de producción o, en otras palabras, al carácter del trabajo. Pero, no obstante el papel rector del factor social en la reproducción humana, éste no debe entrar en contradicciones 
antagónicas fuertes con el lado biológico del proceso. Valga anotar que el genofondo es el sustrato material de todo el complejo de mecanismos organizativos integrantes de la actividad reproductiva del hombre.

Sintetizando lo dicho, le damos la palabra a los fundadores del marxismo: el hombre tiene "siempre ante sí naturaleza histórica e historia natural" (Marx, Engels, Obras completas, $2^{\mathrm{a}}$. ed., T. 3: 43). Además, “...la primera premisa de cualquier historia humana es, por supuesto, la existencia de los individuos" (Ibíd.: 19). En esta misma línea, un existencialista centroamericano afirma:

"si Dios no existe, hay al menos un ser que existe antes de poder ser definido por concepto alguno, y que tal ser es el hombre o como dice Heidegger, "la realidad humana", (Mora, 1964: 18).

Esas son las premisas generales y necesarias en la revelación de la esencia del proceso de reproducción del hombre como fenómeno biosocial adaptativo, a partir del cual se realiza unitariamente la reproducción de la vida, de los medios para la vida y de la sociedad.

\section{Bibliografía}

Alexeiev, V.P. (1969). De los animales al hombre. Moscú: Sov. Rossia.

Andreev, I.L. (1988). Origen del hombre y la sociedad. Moscú: Mysl.
Araya, E. (1991). "Esencia de la naturaleza humana según Santo Tomás de Aquino". San José: Rev. de filosofía de la UCR, vol. XXIX, No. 69.

Bertalanffy, L. von. (1981). A systems view of man. Cal.: Westview press.

Blázquez, N. (1984). “Ética de la reproducción humana según el Warnock Report”. Studium: revista de filosofía y teología. Vol. 24, No.3.

Blázquez, N. (2000). Bioética. La Nueva ciencia de la vida. Madrid: Biblioteca de autores cristianos.

Bolk, Louis (1971). La génesis del hombre. En "La nueva imagen del hombre". Buenos Aires. Editor: Rodolfo Alonso.

Boriskovski, P.I. (1979). El pasado primitivo del hombre. Leningrado: Nauka.

Chanyshev, A.N. (1981). Curso de lecciones sobre filosofía antigua. Moscú: Byshaia shkola.

Darwin, C. (1977). El origen del hombre. La selección natural y la sexual. México: Editora Nacional.

Dubinin, N.P. (1971). La genética y el futuro de la humanidad. Moscú: Znanie.

Dubinin, N.P. (1972). Lo social y lo biológico en el problema actual del hombre // Preguntas filosóficas, Nos. 10 y 11.

Dubinin, N.P. (1981). "Algunos problemas conceptuales de la biología actual". Filosofía y los problemas conceptuales de la ciencia actual: XVI congreso mundial de filosofía. Moscú: Nauka.

Dubinin, N.P. (1983). ¿Qué es el hombre? Moscú: Mysl. 
Dubinin, N.P., Shevchenko, Iu.G. (1976). Algunas cuestiones sobre la naturaleza biosocial del hombre. Moscú: Nauka.

Efimov, Iu.I. (1981). Problemas filosóficos de la teoria de la antroposociogénesis. Leningrado: Nauka.

Engels, F. (1982). Dialéctica de la naturaleza. Moscú: Politizdat.

Giosler, K.O. (1967). Sobre la esencia de la vida. Moscú: Progreso.

Giralt, M. de los A. (1975). El devenir de la esencia en Xavier Zubiri. San José: Edit. Universidad de Costa Rica.

Holbach, P.A. (1963). Obras escogidas en dos tomos. Moscú: Edit. de literatura socioeconómica. T. I.

Iugai, G.A. (1985). Teoría general de la vida. Moscú: Mysl.

Kalaikov, I.D. (1983). Progreso social y biología del hombre. Sofía: Nauka y izkustvo.

Kalaikov, I.D. (1984). Civilización y adaptación. Moscú: Progreso.

Kostov, P. (1982). Antropogénesis y unidad sociobiológica en el hombre. Sofía: Filos. mysl.

Kuczynski, J. (1974). Proba ontologii czlowie$k a$. W-wa: Studia filoz.

Kulikova, S.G. (1969). Hacia el problema de la correlación de lo social y lo biológico en la dinámica demográfica // Cuestiones sociológicas y económicas de la medicina. Rostov en el Don.

La Mettrie, J.O. (1976). Obras. Moscú: Mysl.

Lenin, V.I. (1989). Materialismo y empiriocriticismo. Moscú: Politizdat.
Lenin, V.I. Nuevamente sobre los sindicatos. Obras completas: T. 42.

Lomov, B.F. (1977). El problema de lo socialy lo biológico en la psicología // Lo biológico y lo social en el desarrollo humano. Moscú.

Löther, R. (1974) "Die Dialektik von Biologischem und Gesellschaftlichen im wissens-chaftlichen Menschenbild”. Berlín: Einheit, Jg. 29, N7.

Louis, D. (1964). El hombre y la evolución. Moscú: Progreso.

Marx, C., Engels, F. (1983). Obras escogidas. Moscú: Progreso.

Marx, Engels. Ideología alemana. Obras completas: $2^{a}$. edic., T.3.

Mayr, E. (1968). Especie zoológica y evolución. Moscú: Mir.

Mayr, E. (1974) "El hombre como especie biológica”. Rev. Naturaleza, No.2.

Méndez, T. (1989). La reproducción humana en la revolución científico-técnica. Odessa: Tesis doctoral.

Méndez, T. (2002). "La reproducción humana en la revolución científico-técnica". Espiga: revista de la Escuela de Ciencia Sociales- UNED. San José.

Mora, J.L. (1964). Esencia y existencia del hombre. León, Nicaragua: Tesis.

Muraviov, V.V. (1978). Correlación de los factores sociales y biológicos en los procesos demográficos // Problemas de la filosofia marxista-leninista y de la sociología. Leningrado.

Pletnikov, Iu. (1983). "El problema del hombre como problema de producción y reproducción de la vida inmediata" // La personalidad en el mundo actual: Discursos 
preparatorios de los científicos soviéticos hacia el XVII Congreso mundial "Filosofía y cultura" (Montreal, Canadá, 2127 de agosto de 1983). Moscú.

Rubin, I. Ia. (1971). El problema de la correlación de lo biológico y lo social en la reproducción de la población humana // El problema de la demografía y los recursos laborales, No. 2, Minsk.

Scheler, Max (1967). La idea del hombre y la historia. Buenos Aires: Siglo Veinte.

Scheler, Max (1972). El puesto del hombre en el cosmos. Buenos Aires: Losada.
Severtsev, A.N. (1922). Evolución y psiquis. Moscú: M. y S. Sabashnikobyj.

Sklovski, I.S. (1987). Universo, vida, razón. Moscú: Nauka.

Stine Gerald James (1977). Biosocial genetics: Human heredity and social issues. N.Y.: Macmillan; L.: Collier Macmillan, XI.

Vernadski, V.I. (1977). Meditaciones del naturalista. Moscú: Nauka. Libro 2.

Wilson, E.O. (1978). On human nature. Cambridge (Mass.); London: Harvard univ. press- XII. 